\title{
Determination of Antioxidant Capacity, Total Phenolic and Flavonoid Contents of Zahdi Date Seed and Their Effect on Beef Patties
}

\author{
Nareman Adeem Shnaa Aljazya), Aum El-Basher H.J.Al-Mossawi ${ }^{\text {b) }}$ and Ali Khudair Jaber Al Rikabi ${ }^{\text {c) }}$ \\ Department of Food Science, College of Agriculture, University of Basrah, Iraq. \\ a) Corresponding Author: nareman.shnaa@uobasrah.edu.iq \\ b) aum_elbashar.jaber@uobasrah.edu.iq \\ c) ali.jaber@uobasrah.edu.iq
}

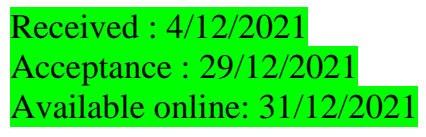

\begin{abstract}
The study included preparation of aqueous (As) and alcoholic (ethanolic Es , methanolic Ms ) and oil extracts (Os) of Zahdi date seeds (Zs)(Phoenix dactylifera) . Chemical content of date seed was studied and the total content of phenols and flavonoids were estimated for prepared extract. Bioactive compounds of this extract was identification by Gas Chromatography Mass Spectrometer GCl MS. Antioxidant activity , reducing power, chelating of iron ions of extract was studied, then used the extract which gave highest antioxidant activity in beef patties with two concentrations $0.05 \%$ and $0.1 \%$ to test their efficiency in oxidative inhibition and prolonging the reservoir age of stored beef patties in refrigerated for 10 - days and following chemical indicators in Peroxide value(PV), Thiobarbituric acid(TBA) in treated beef patties. Moisture, protein ,oil, ash and carbohydrate contents of Zs $9.36 \%$, $4.87 \%, 8.56 \%, 1.34 \%, 75.87 \%$ respectively . All extracts containing many bioactive compounds that identification of GC-MS and differented in their percentage according to the type of extract. All extracts share with some bioactive compound as 1-(+)-Ascorbic acid 2,6-dihexadecanoate, gamma.sitosterol ,Octadecanoic 5-Methyl-2-ethylamino-2thiazoline, acid, Hexadecanoic acid and 2-hydroxy-1-(hydrixymethyl)ethylester. Alcoholic extracts (Es and Ms) exhibited the highest content of phenolic compound compared with As was $67.32 \mathrm{mglml}$ for Es , Ms was $65.32 \mathrm{mglml}$ While the total content of flavonoids for As 33.32mglml and Es $52.16 \mathrm{mglml}, 46.16 \mathrm{mglml}$ for Ms , As and alcoholic extracts of Zs exhibited antioxidant activity was $88.70 \%$ for Es and $87.02 \%$ for Os , $85.22 \%$ for Ms, but As was the lowest $43.01 \%$. The prepared extracts showed the higher reducing power was 2.63 and Chelating of iron ions 60.93 $\%$ and for Es, There was a significant decrease $(\mathrm{P}<0.05)$ in peroxide value and thiobarbituric acid in beef patties treated with ethanolic extracts compared with control.
\end{abstract}

Keywords. Total phenolic content, Zahdi date seed, Antioxidant activity, Lipid oxidation.

\section{INTRODUCTION}

New studies found that Date seeds contain valuable bioactive compounds such as Phenolic Compounds, Flavonoids , Antioxidants and Fibre dietary , Percentage these compounds was highest than that presenting in flesh part, and that high levels of $\alpha$-Tocopherol , Ascorbic acid, Glutathione, and Sinapic acid, Caffeic acid, Protocatechenic acid as Polyphenol compounds [1-2], and identificated many of aromatic compounds in date seed such as alcohols, esters ,aldehydes, terpenes ,ketones, saturated and unsaturated hydrocarbons [3]. Oxidation due to free radical that considers is the main factor of disease, Scientific evidence show that oxidative stress is a cause of fat oxidation [4], functional change of endothelial that leading to atherosclerosis, All combinations of active compounds found in date seed are assumed to be able to affect lipid profile by increasing HDL level and decreasing total cholesterol, triglyceride and LDL level, thus atherogenic index will decrease as well [5]. Date seeds that has been considered as a good example of functional food and their a large role of food avidities and extend of shelf life [6] .This study came with the aim of knowing the effect of date seed extracts as a natural antioxidant to be used in date seed extracts as food additives to delay the oxidation of fats in various foods, especially meat products. 


\section{MATERIALS AND METHODS}

\section{- Plant Material}

Date seed obtained from date fruit (Phoenix dactylifera var. Zahdi) were procured from local market, Basrah. Dry seeds were ground into a fine powder using a blender (binder USA) and sieved through stainless steel sieve of 40 mesh. The powder was placed in polyethylene bags and stored in a refrigerator until use, and were procured beef from Basrah .

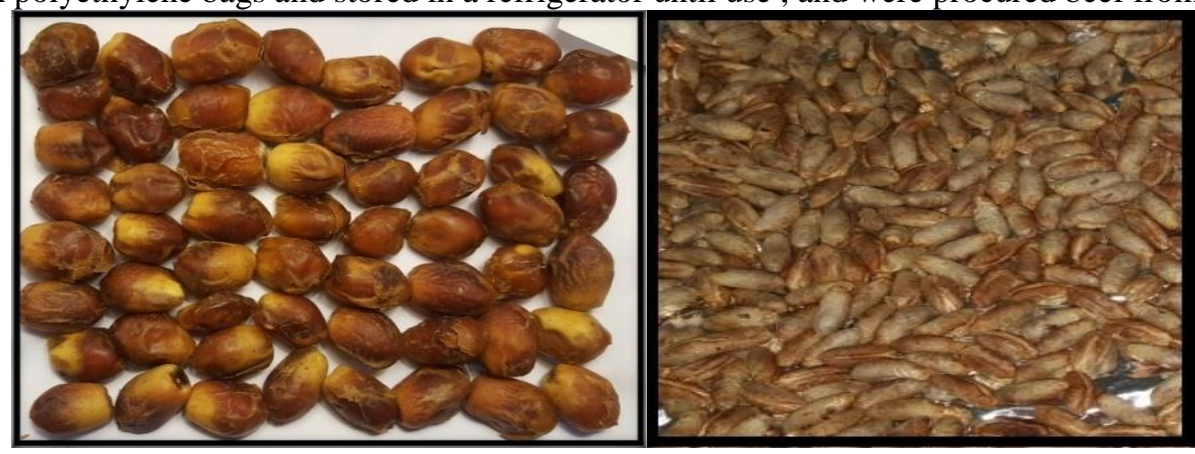

FIGURE 1. Photographs of date and seed.

\section{- Chemical Composition of Date Seed}

Moisture, protein, oil ,Ash and carbohydrate contents of date seed were determinate according to the Association of Official Analytical Chemists [7] .

\section{- Preparation of Date Seeds Extract}

\section{A- Water Extracts}

Followed of method [8], Date seed powder (20g) was mixed with500ml of distilled water . Thereafter ,the mixtures were placed in shaking incubator for 24 hours at $28 \mathrm{C}^{\circ}$ then centrifuged at $2500 \mathrm{rpm}$ for ten minutes, then filtered using funnel with Whitman No.1, concentrated of filtrate by rotary vacuum evaporator to thick liquid then placed in incubator at $37 \mathrm{C}^{\circ}$ for 48 hours get at dry powder of extract, Put in glass containers and refrigerated at $4 \mathrm{C}^{\circ}$.

\section{B- Ethanolic Extract}

Preparation of ethanolic extracts by weighted $100 \mathrm{~g}$ of date seed powder which dissolved by $500 \mathrm{ml}$ ethanol $(70 \%)$ and mixed them well and left for 24 hours at laboratory temperature $\left(25-30 \mathrm{C}^{\circ}\right)$. The mixtures were filtrated by whatman No.1 and concentrated by rotary vacuum evaporator at $40 \mathrm{C}^{\circ}$ and left at laboratory temperature to get dry powder . Put in glass containers and refrigerated at $4 \mathrm{C}^{\circ}[9]$.

\section{C-Methanolic Extract}

Followed steps in paragraph B to get at ethanolic date seed extracts.

\section{D- Oil Extract}

Date seed oil was extracted from date seed powder by the method of [10], A weighed 10g of Sample and was solved in $20 \mathrm{ml}$ of chloroform, $40 \mathrm{ml}$ methanol and $1 \mathrm{ml}$ distilled water and mixed them well by glass rood for five minutes. Then , 20 $\mathrm{ml}$ of chloroform was added to mixture and mixed well for other five minutes. Thereafter, added to $20 \mathrm{ml}$ distilled water with mixing and left for 15 minutes, Then was filtered by whatman No.1, The mixture placed in separation funnel, Afew minutes later, two phase was formed. The lower chloroformic phase containing the total lipids was dried and calculated by weighing a dry beaker and beaker with oil after chloroform evaporation .

\section{- Determination of Total Phenols}

Total phenols in zahdi date seed was determined calorimetrically at $760 \mathrm{~nm}$ with the Folin- Ciocalteau reagent as previously done by [11].

\section{- $\quad$ Standard Curve}

Standard solution from Gallic acid used for calculated Total phenols in extract at concentration ranged from 10 to $100 \mathrm{mg} / \mathrm{ml}$ dependent on graphic relationship between Acid concentration and Absorption at 760nm wave length (Figure 2) 


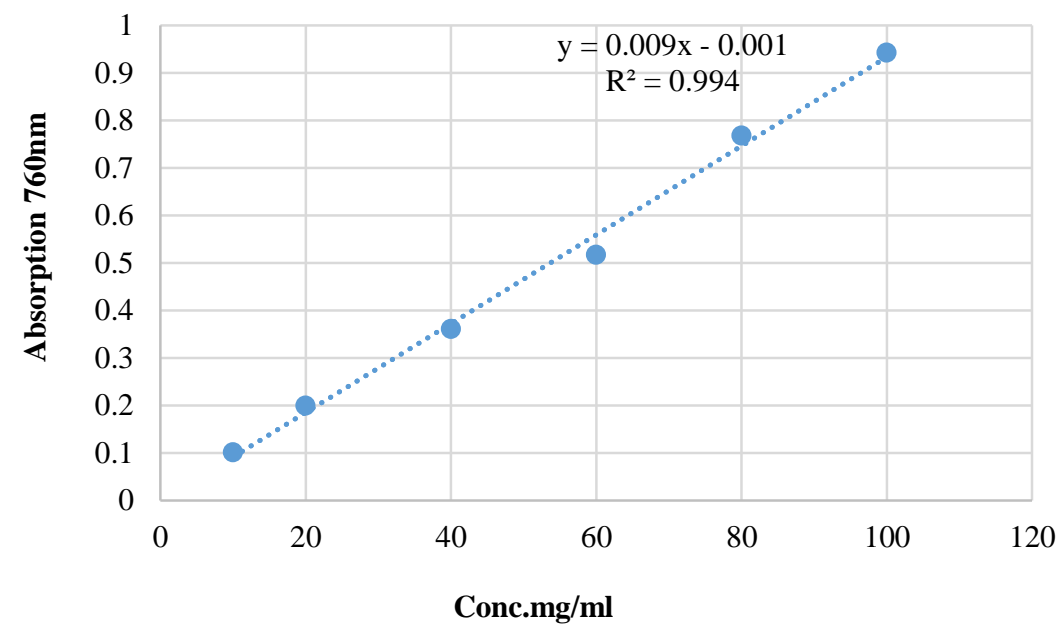

FIGURE 2.Standard curve of Gallic acid.

- Flavonoids Determination of Total

Date seed powder $(1 \mathrm{~g})$ was dissolved in $1.5 \mathrm{ml}$ ethanol, added to it an equal volume of Aluminium chloride $\mathrm{AlCl}_{3 .} 6 \mathrm{H}_{2} \mathrm{O}$ $(2 \%)$ which prepared in $100 \mathrm{ml}$ methanol, mixed the ingredients well and the absorbance was determined at $415 \mathrm{~nm}$.

\section{- $\quad$ Standard Curve}

A standard curve was prepared using rutin in the range $(10-200 \mathrm{mg} / \mathrm{ml})$. Thereafter, Flavonoids content was determined through the graphic relationship between rutin concentration and absorption at $415 \mathrm{~nm}$ (Figure 3 ).

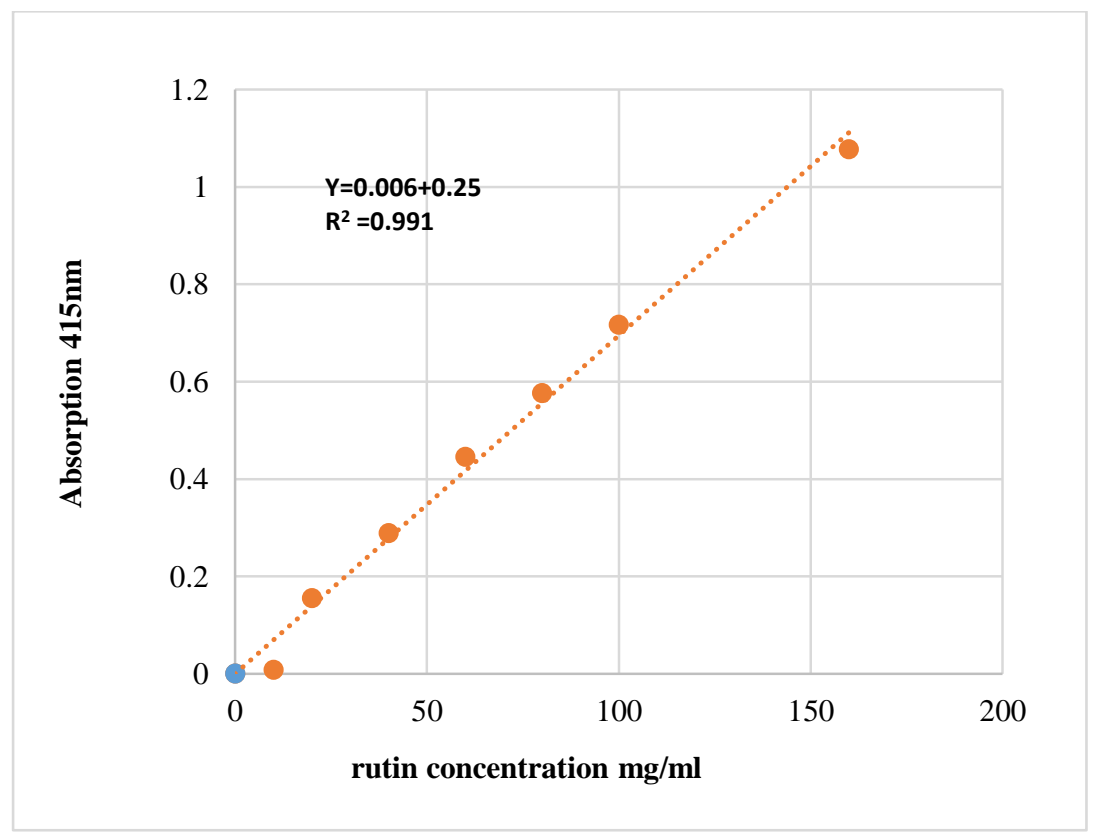

FIGURE 3. Standard curve of rutin. 


\section{- GC/MS Analysis}

Bioactive compounds of the zahdi seed extracts were determined by GC/MS analysis in GC/MS Laboratory /Agriculture college / Basrah university . A Gas Chromatograph QP210 ULTRA ( Make : SHIMADZU, Japan). The GC/MS instrument conditions are given in Table 1.

TABLE 1. Operating conditions for the GC/MS.

\begin{tabular}{cc}
\hline Mass Spectrometer & Gas Chromatography \\
\hline Ionsource Temp : $200.00^{\circ} \mathrm{c}$ & Column Oven Temp $: 40^{\circ} \mathrm{c}$ \\
Interface Temp : $250.00^{\circ} \mathrm{c}$ & Injection Temp : $250.00^{\circ} \mathrm{c}$ \\
Solvent Cut Time $: 3.00 \mathrm{~min}$ & Injection Mode $:$ Split \\
Start Time $: 3.00 \mathrm{~min}$ & Flow Control Mode: Linear Velocity \\
End Time $: 28.00 \mathrm{~min}$ & Pressure $: 49.5 \mathrm{kpa}$ \\
ACQ Mode: Scan & Total Flow : $34.0 \mathrm{ml} l \mathrm{~min}$ \\
Event Time $: 0.50 \mathrm{sec}$ & Column Flow $: 1.00 \mathrm{ml} l \mathrm{~min}$ \\
Scan Speed: 1000 & Linear Velocity $: 36.1 \mathrm{~cm} l \mathrm{sec}$ \\
Start $\mathrm{m} l \mathrm{z}: 50.00$ & Purge Flow $: 3.0 \mathrm{ml} l \mathrm{~min}$ \\
End $\mathrm{m} l \mathrm{z}: 500.00$ & Split Ratio $: 30.0$ \\
\cline { 2 - 2 }
\end{tabular}

\section{- $\quad$ Measurement of Antioxidant Activity}

\section{A-DPPH (1,1-Diphenyl-2-Picrylhydrazyl) Free Radical scavenging Activity Assay:}

The free radical scavenging activity of the extract, based on scavenging of the stable 1,1-diphenyl-2-picrylhydrazyl (DPPH) free radical was estimated according to the procedure described by [12] . A sample of the extract (1 ml) was mixed with $4 \mathrm{ml}$ methanol and $1 \mathrm{ml}$ of reagent solution $(10 \mathrm{mM}$ of DPPH in ethanol ). The control contained only DPPH solution in place of the sample. The mixture was vigorously shaken and left to stand at room temperature. After 30 minutes the decrease in absorbance of test mixture (due to quenching of DPPH free radicals) was read at $517 \mathrm{~nm}$. The scavenging effect was calculated using the expression :

$$
\text { Inhibition } \%=\{1-[\text { Abs sample } / \text { Abs control }]\} \times 100
$$

\section{B-Reducing Power Assay :}

$0.25 \mathrm{ml}$ sample of $\mathrm{Zs}$ extract was mixed with phosphate buffer $(0.25 \mathrm{ml})$ and potassium ferricyanide $(2.5 \mathrm{ml})$. The mixture was incubated at $50^{\circ} \mathrm{C}$ for $20 \mathrm{~min}$. Aliquots of trichloroacetic acid $(2.5 \mathrm{ml})$ were added to the mixture, which was then centrifuged at $3000 \mathrm{rpm}$ for $10 \mathrm{~min}$. The upper layer of solution $(2.5 \mathrm{ml})$ was mixed with distilled water $(2.5 \mathrm{ml})$ and a freshly prepared ferric chloride solution $(0.5 \mathrm{ml})$. The absorbance was measured at $700 \mathrm{~nm}$. A control was prepared without adding extract . Increase in absorbance of mixture was indicated high reducing power [13].

\section{C- Chelating Activity of Ferrous Ion :}

Chelating activity towards $\mathrm{Fe}^{+2}$ was measured by the method of [14]. $1 \mathrm{ml}$ of Zs extract was mixed with ethyl acetate ( $3.7 \mathrm{ml}) .0 .1 \mathrm{ml}$ of ferrous chloride $(2 \mathrm{mM})$ was added to mixture, and $0.2 \mathrm{ml}$ of 8 - Hydroxy quinoline $(5 \mathrm{mM})$, The mixture was mixed and left at room temperature for 10min. The Absorbance was measured at $562 \mathrm{~nm}$, EDTA2Na was used as standard . A control was prepared without adding extract . Chelating activity was calculated using the expression :

Chelating activity $\%=\{1-[$ Abs sample $/$ Abs control $]\} \times 100$

\section{- Using of Ethanolic Extract as Antioxidant in Beef Patties}

\section{A- Preparation of Beef Patties}

The Beef were purchased from the local market in Basrah, Beef patties were prepared after wished it and minced using a meat grinder. Then, added it $10 \%$ of fat and $2 \%$ salt . Meat mince was devided into 3 sample : 1-First sample : it was control without adding extract , 2-Second sample : ethanolic extract was added $(0.05 \%)$, 3- Third sample : ethanolic extract was added $(0.1 \%)$. Beef patties were placed in polyethylene bags and stored in refrigerator at $4^{\circ} \mathrm{C}$ for 10 days . At designated time $(0,3,7$, and 10 days $)$, samples were taken for determination of peroxide value(PV) [15] and thiobarbituric acid-reactive substances (TBARS) [16] .

\section{- $\quad$ Statistical Analysis}

All experiments were carried out in triplicate . Data were subjected to the analysis of variance (ANOVA) . Statistical analysis was carried out using the Statistical Package analysis for Social Science (SPSS ) [17] . 


\section{RESULTS AND DISCUSSION}

\section{- Chemical Composition of Zahdi Date Seed}

Table 2. presents the average chemical composition of Zahdi date seed . Zs contained 9.36\% moisture . Concerning the crude lipid contents, this value was $8.56 \%$ and it is comparable to the results reported by [18] at studied chemical composition of Zahdi date seed were found \%8.14, Protein were 4.87\%, our results are smiliar to those from [19], who reported a protein content $4.71 \%$ in Khalas date seed. The ash content was $1.34 \%$ and a comparable result was found by [20] (1.20\%) and [21] (1.25\%). The total carbohydrates content was found $75.87 \%$.

\begin{tabular}{cc}
\multicolumn{2}{l}{ TABLE 2. Proximate composition of Zahdi date seed. } \\
\hline Component \% & Composition of date seed \\
\hline Moisture & 9.36 \\
Lipid & 8.56 \\
Protein & 4.87 \\
Ash & 1.34 \\
Carbohydrate & 75.87 \\
\hline
\end{tabular}

- GC/MS Analysis

\section{A - Aqueous Extract Composition of Zahdi Date Seed}

The identification of Aqueous extract composition(As) of Zs was performed by Gas Chromatography Mass Spectrometry (GC/MS). The result is shown in figure4.

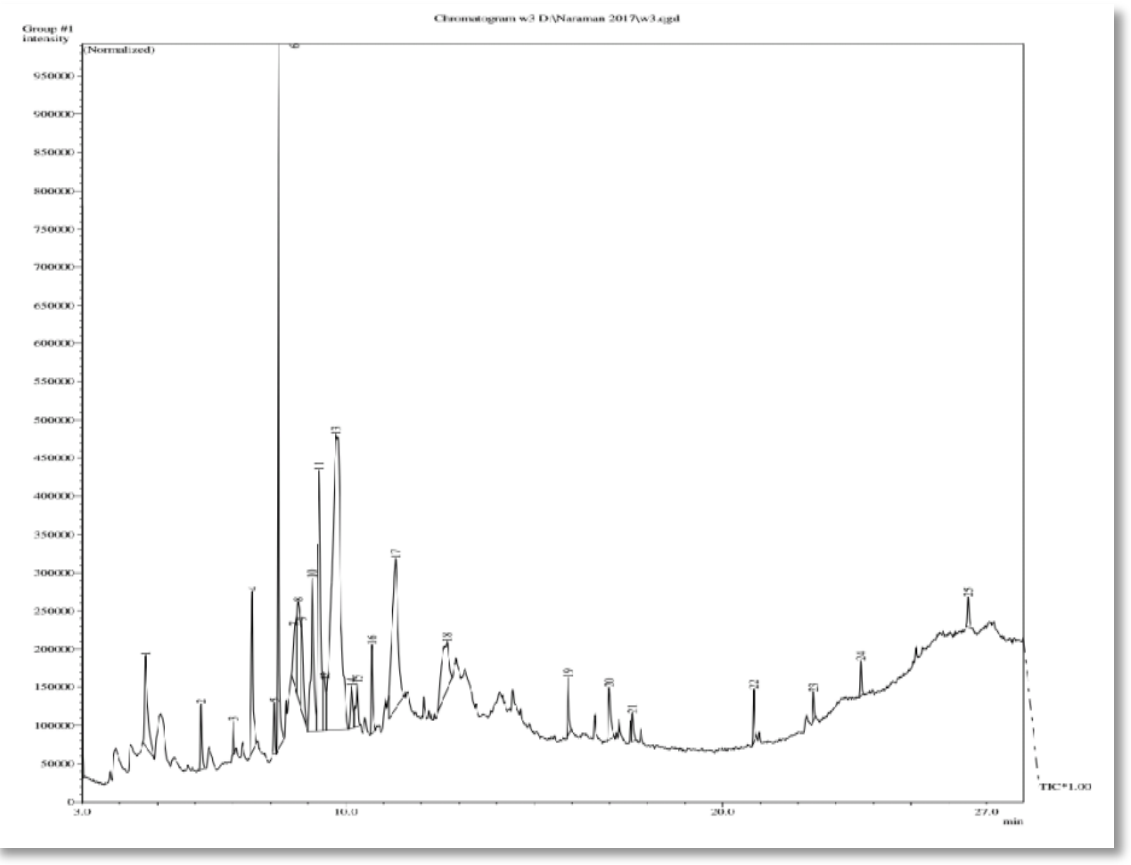

FIGURE 4. GC/MS diagram of As.

The Aqueous extract composition of the Zs that detected through the study are listed in the table . The results show that the 3-methyl mannoside had the highest amount 30.54\% while 4-Ketopimelic had the lowest amount $0.39 \%$, Also , the results show another bioactive components like 4H-pyran-4-one,2,3-dihydro-3,5dihydroxy-6-methy and gamma-sitosterol that the percentage are $11.70 \%$ and $0.57 \%$ respectively .

TABLE 3.Zahdi date seed composition.

\begin{tabular}{cccc}
\hline No & Identified compounds & Retention time (min) & Weight \% \\
\hline 1 & Ethanamine, 2-methoxy-N-(2-methoxyethyl)-N-methyl- & 4.680 & 3.39 \\
2 & 2,4-Dihydroxy-2,5-dimethyl-3(2H)-furan-3-one & 6.155 & 1.04 \\
3 & 4-Ketopimelic & 7.010 & 0.39 \\
4 & Cyclohexanamine, N-3-butenyl-N-methyl- & 7.514 & 3.46 \\
5 & Ethanamine, N-ethyl-N-nitroso- & 8.105 & 0.77 \\
6 & 4H-Pyran-4-one, 2,3-dihydro-3,5-dihydroxy-6-methyl- & 8.210 & 11.70 \\
\hline
\end{tabular}




\begin{tabular}{|c|c|c|c|}
\hline No & Identified compounds & Retention time (min) & Weight \% \\
\hline 7 & 4H-Pyran-4-one, 3,5-dihydroxy-2-methyl- & 8.633 & 2.65 \\
\hline 8 & 2(3H)-Furanone, 5-ethyldihydro- & 8.732 & 3.50 \\
\hline 9 & 1,2-Benzenediol & 8.825 & 2.44 \\
\hline 10 & 2-Furancarboxaldehyde, 5-(hydroxymethyl)- & 9.105 & 5.43 \\
\hline 11 & 2-(1-Hydroxyethyl)-2-methyl-1,3-oxathiolane & 9.289 & 8.06 \\
\hline 12 & 1-Propanol, 3-chloro-, acetate & 9.450 & 1.94 \\
\hline 13 & 3-Methylmannoside & 9.742 & 30.54 \\
\hline 14 & Butanedioic acid, monomethyl ester & 10.152 & 1.26 \\
\hline 15 & Butanedioic acid, 2-hydroxy-2-methyl-, (S)- & 10.303 & 1.33 \\
\hline 16 & $\begin{array}{c}\text { '-(3H-Indol-3-ylmethylene)-hydrazino]-5-methyl-[1,2,4]triazol-4- } \\
\text { ylamine }\end{array}$ & 10.690 & 1.52 \\
\hline 17 & Sucrose & 11.319 & 10.77 \\
\hline 18 & Ethyl trans-3-methyl-2-oxiranecarboxylate & 12.686 & 4.60 \\
\hline 19 & Pentadecanoic acid & 15.897 & 0.98 \\
\hline 20 & Pent-1-en-3-one, 4,4-dimethyl-1-(4-morpholino)- & 16.990 & 1.43 \\
\hline 21 & 6-Octadecenoic acid, (Z)- & 17.605 & 0.50 \\
\hline 22 & Hexadecanoic acid, 2-hydroxy-1-(hydroxymethyl)ethyl ester & 20.826 & 0.79 \\
\hline 23 & Octadecanoic acid, 2,3-dihydroxypropyl ester & 22.412 & 0.44 \\
\hline 24 & Hexatriacontane & 23.667 & 0.52 \\
\hline 25 & .gamma.-Sitosterol & 26.519 & 0.57 \\
\hline
\end{tabular}

\section{B- Ethanol Extract Composition of Zahdi Date Deed}

The ethanolic extract composition of the Zs that detected through the study are listed in the table 4.and Figure5. The results show that the 1-(+)-Ascorbic acid 2,6-dihexadecanoate had the highest amount 18.09\% and Hexatriacontane 14.12\%, Also, the results show another bioactive components like Quinoline,2-methyl,1-oxide and gamma-sitosterol are $2.09 \%$, $3.04 \%$ respectively . Our results was in agreement with those found by [22], who identified essential oil composition was extracted from Capers ( Capparis spinosa) by GC/MS As formation Hexatriacontane are $15.87 \%$, This compound are possess many of biological properties such as antioxidant, antibacterial and therapeutic agent .

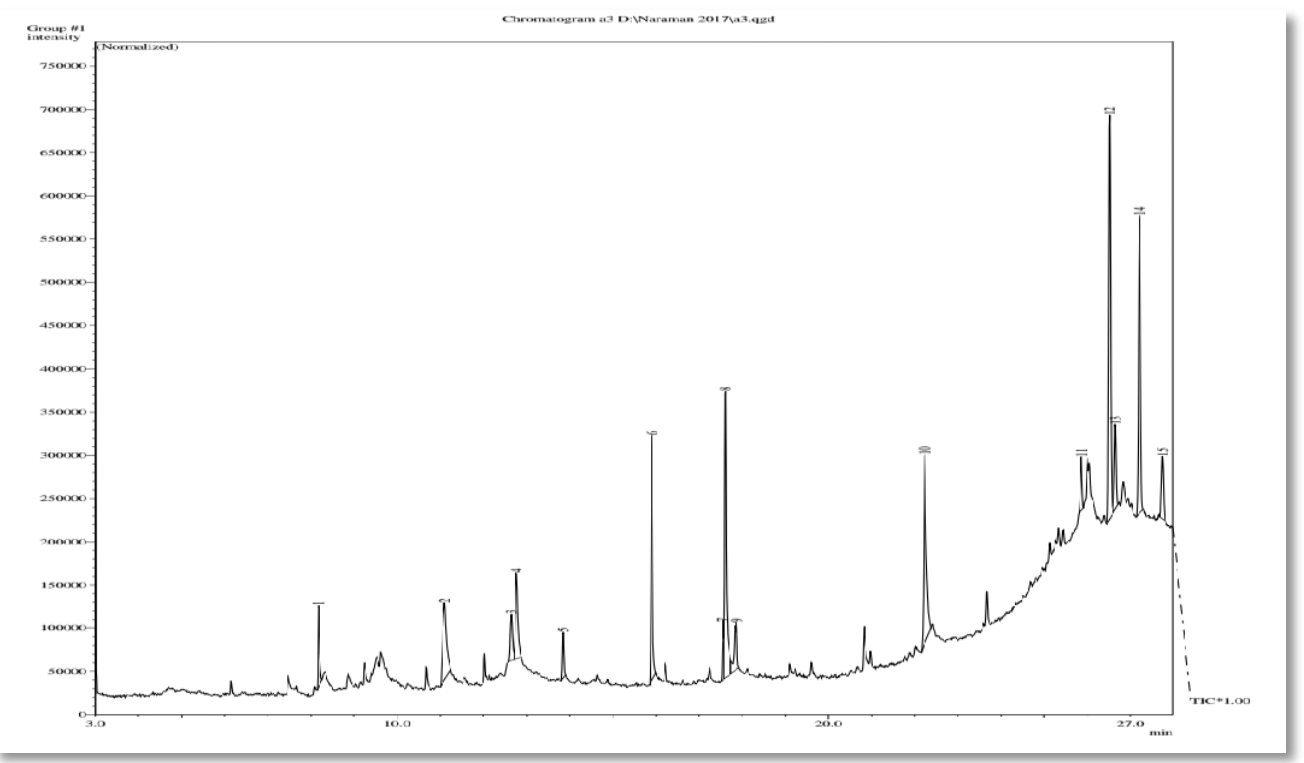

FIGURE 5. GC/MS diagram of Es. 
TABLE 4. Es .Zahdi date seed composition.

\begin{tabular}{cccc}
\hline No & Identified compounds & Retention time (min) & Weight \% \\
\hline 1 & Ethanamine,2-methoxy-N- (2-methoxyethyl)-N-methy & 8.178 & 2.73 \\
2 & 4-H-Pyran-4-one,2,3-dihydro-3,5-dihydroxy-6-methy & 11.096 & 7.51 \\
3 & 2-Furancarboxaaldehyde,5-(hydroxymethyl)- & 12.649 & 2.57 \\
4 & 2-(1-Hydroxyethyl)-2-methyl-1,3-oxathiolane & 12.761 & 5.26 \\
5 & 5-Methyl-2-ethylamino-2-thiazoline & 13.848 & 1.57 \\
6 & Ethylene glycol butyl ether, trimethyl silyl ether & 15.901 & 8.48 \\
7 & Quinoline, 2-methyl- 1-oxide & 17.550 & 2.09 \\
8 & 2-Butanone, 4-hydroxy-3-methyl & 17.613 & 13.20 \\
9 & 1,2-Benzenediol & 17.866 & 3.61 \\
10 & Ethyl trans-3-methyl-2-oxiranecarboxylate & 22.230 & 11.91 \\
11 & Sucrose & 25.863 & 2.18 \\
12 & 1-(+)-Ascorbic acid 2,6-dihexadecanoate & 26.522 & 18.09 \\
13 & Hexadecanoic acid,2-hydroxy-1-(hydroxymethyl)ethy & 26.652 & 3.63 \\
14 & ester & 27.212 & 14.12 \\
15 & Hexatriacontane & 27.742 & 3.04 \\
\hline
\end{tabular}

\section{C-Methanol Extract Composition of Zahdi Date Seed}

The methanolic extract composition of the Zs that detected through the study are listed in the table 5.and Figure 6. The results show that the 4H-pyran-4-one,2,3-dihydro-3,5-dihydroxy-6-methyl had the highest amount 39.18\% follwed Hexadecanoic acid ,2-hydroxy-1-(hydroxymethyl)ethylester 27.48\% and Octadecanoic acid,2,3-dihydroxypropylester was called 1-Monostearin or Glycerol monostearate (GMS) that using as emulsifier in food products, additives agent and antistaling in bread industry [23] .

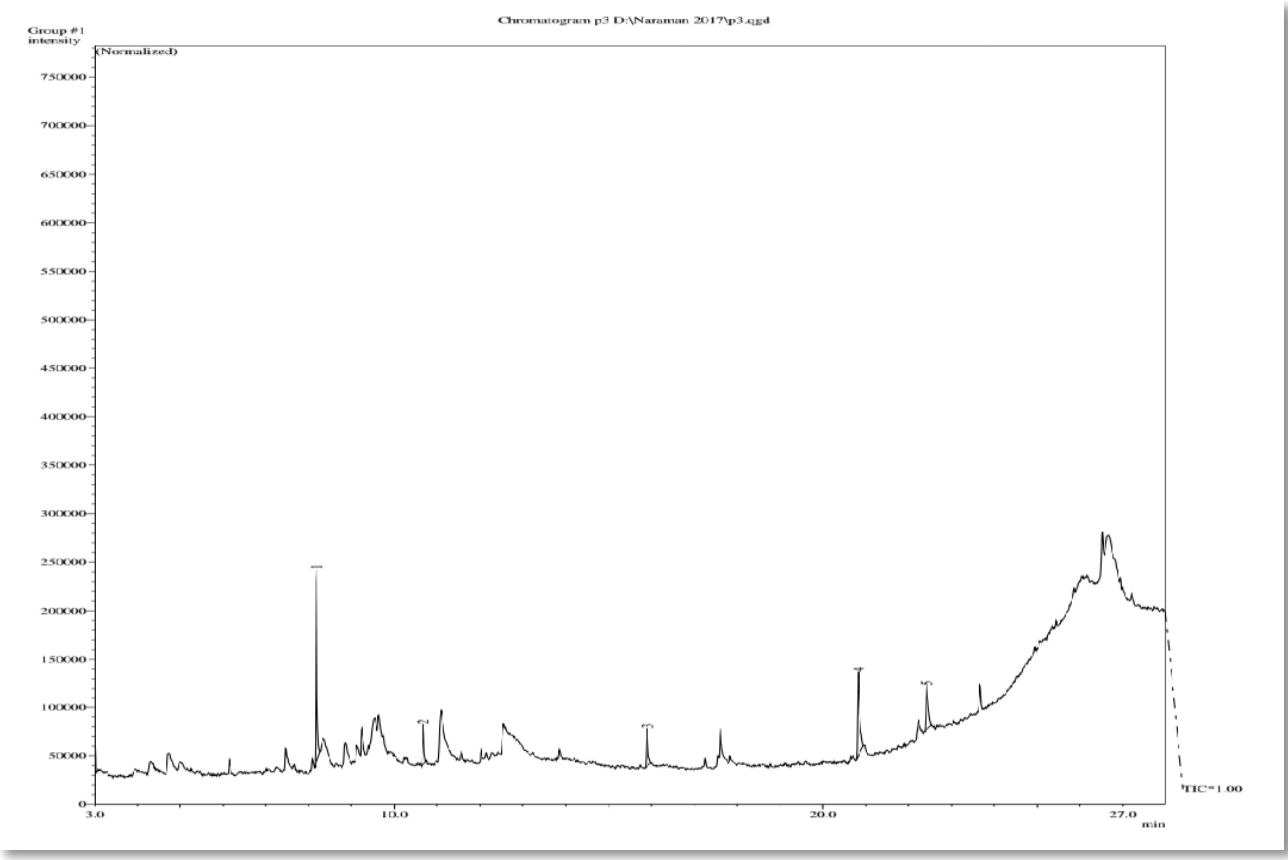

FIGURE 6. GC/MS diagram of Ms. 
TABLE 5. Ms Zahdi date seed composition

\begin{tabular}{crcc}
\hline No & Identified compounds & Retention time (min) & Weight \% \\
\hline 1 & 4H-Pyran-4-one, 2,3-dihydro-3,5-dihydroxy-6-methyl- & 8.180 & 39.18 \\
2 & 3-[N'-(3H-Indol-3-ylmethylene)-hydrazino]-5-methyl-[1,2,4]triazol-4-ylamine & 10.676 & 7.74 \\
3 & 1-(+)-Ascorbic acid 2,6-dihexadecanoate & 15.901 & 9.67 \\
4 & Hexadecanoic acid, 2-hydroxy-1-(hydroxymethyl)ethyl ester & 20.831 & 27.48 \\
5 & Octadecanoic acid, 2,3-dihydroxypropyl ester & 22.422 & 15.92 \\
\hline
\end{tabular}

\section{- Total Phenolic and Flavonoids Contents}

Total phenolic and flavonoids contents of Zs using water or ethanol or methanol as the extraction media at different concentrations are shown in figure 7,8. Alcoholic extracts (Ethanolic and Methanolic) exhibited the highest content of phenolic and flvonoids compounds compared with water extracts $(P<0.05)$. Concerning to phenolics was $67.32 \mathrm{mg} / \mathrm{ml}$ for ethanolic extract. However the present results are much higher than those reported by [24] who found phenolic content in ethanolic extract of date seed $28.22 \mathrm{mg} \mathrm{GAE} / 100 \mathrm{~g}$. The variation within may be owing to variety, growing condition , maturity, season, geographic origin, fertilizer, diseases soil type and storage conditions as well as extraction system as shown in the results of [ 25]. While the total content of flavonoids for aqueous extracts $33.32 \mathrm{mg} l \mathrm{ml}$ and ethanolic extract $52.16 \mathrm{mg} / \mathrm{ml}$ and $46.16 \mathrm{mg} / \mathrm{ml}$ for methanolic extract . Our results are in agreement with those reported by [26] who founded that the acetone $(50 \% \mathrm{v} / \mathrm{v})$ and ethanol $(50 \% \mathrm{v} / \mathrm{v})$ was used as extraction medium for date seeds , total phenolic and total flavonoid contents were higher, compared to that of water extract $(P<0.05)$. Water exhibited poor ability to extract phenolics and flavonoids in the date seed due to the low solubility of these components in water [ 26] . Morever , protein and polysaccharides could be co-extracted when water was used alone for extraction . these substances might cause the fouling for filtration [27].

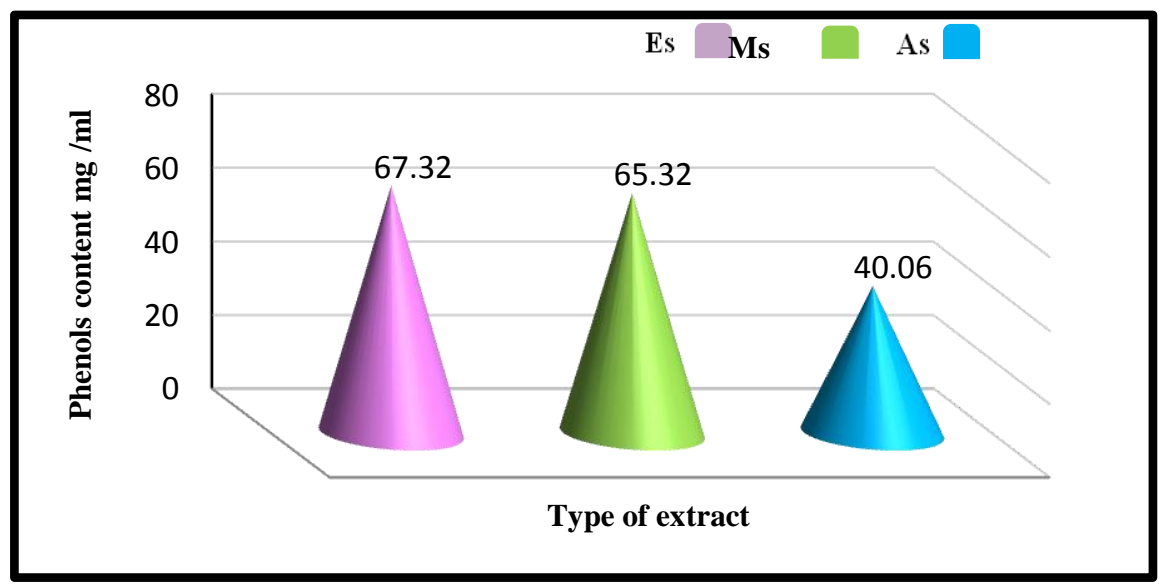

FIGURE 7. Total Phenolics in Zs extracts.

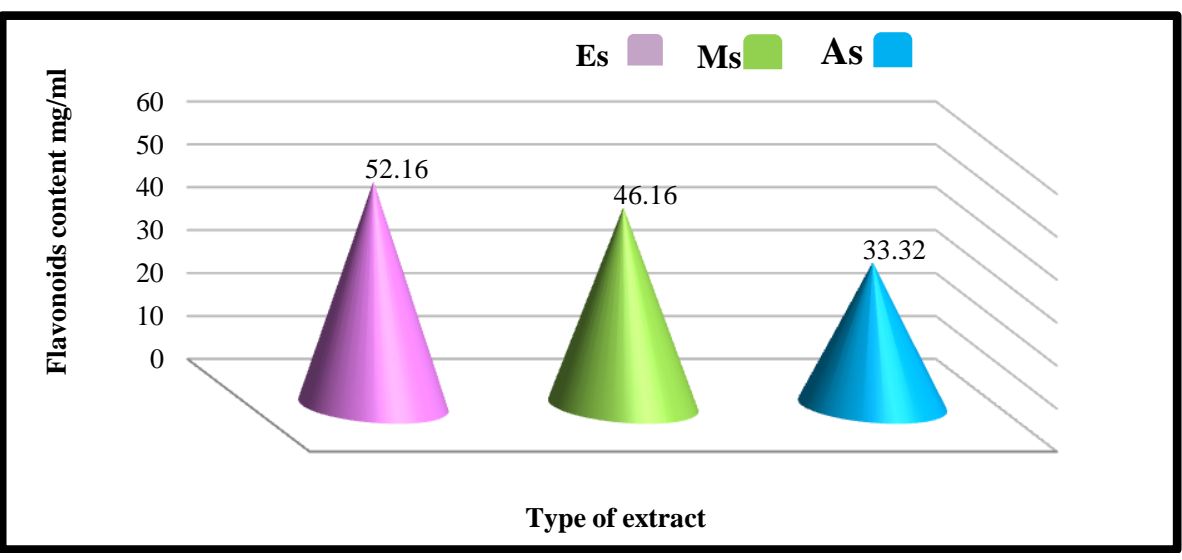

FIGURE 8. Total flavonoids in Zs extracts. 


\section{- Antioxidant Activity of Zs Extracts}

\section{A-DPPH Assay}

DPPH assay based on the ability of antioxidant to scavenge 1,1-diphenyl-2-picrylhydrazyl (DPPH) radical cations . DPPH radical scavenging activity of Zs extracts obtained from ethanol or methanol or water extraction at different concentrations and that compared with Butylated Hydroxy Toluene (BHT) are shown in Figure 9 . The activities increased when the concentration of extracts increased. An aqueous and alcoholic extracts of Zs exhibited antioxidant activity $88.70 \%$ for ethanolic extract and was ad equal to BHT activity $88.00 \%$ at $1.25 \mathrm{mg} / \mathrm{ml}$, and $87.02 \%$ for oil extract and $85.22 \%$ for methanolic extract but aqueous extract was the lowest $43.01 \%$ at the same concentration. The ability of the Zs extracts to scavenge DPPH radical was found to be related to the total phenolic and flavonoid contents . Our results are an agreement with those reported by [ 28] who founded that the antioxidant activity $\left(\mathrm{EC}_{50} \mathrm{mg} / \mathrm{ml}\right)$ of methanolic extracts obtained from two cultivars of date seed between $0.61-0.74 \mathrm{mg} / \mathrm{ml}$ for two types . DPPH radical scavenging activity of date seed extracts reflects their hydrogen donating ability [29]. In general, phenolic compounds capable of donating hydrogen atom are more effective in scavenging DPPH [30].

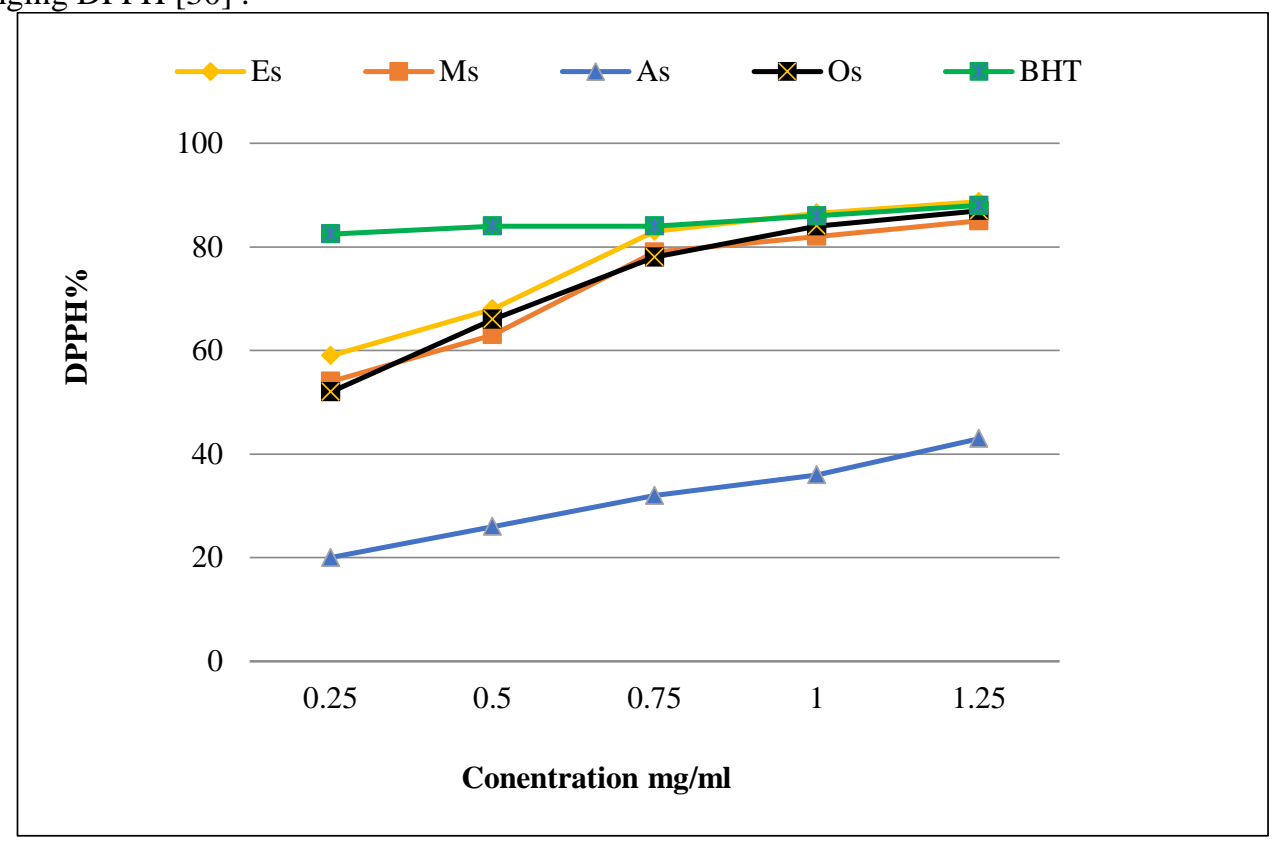

\section{B-Reducing Power}

FIGURE 9. DPPH radical scavenging activity of Zs extracts.

Reducing power is a measure of the ability of the extracts to reduce $\mathrm{Fe}^{+3}$ to $\mathrm{Fe}^{+2}$. Substances which have reduction potential react with potassium ferri-cyanide $\left(\mathrm{Fe}^{+3}\right)$ to form potassium ferro-cyanide $\left(\mathrm{Fe}^{+2}\right)$ which then reacts with ferric chloride to form ferric ferrous complex that has an absorbance maximum at 700nm. The prepared extracts showed reducing power 2.63 for ethanolic extract and that was ad equal to alpha tocopherol , 2.342 for methanolic extract and 1.732 for oil extract and aqueous extract 0.993 at $1.25 \mathrm{mg} / \mathrm{ml}$ (Figure 10). Increase in reducing power of Zs extracts with increasing concentration of the extracts could be related to the increase in total phenolic and flavonoid contents . Date seed extracts has a relatively high reducing power. This might be due to the high antioxidant capacity of the seed extract because antioxidants are strong reducing agents and this is principally because of the redox properties of their hydroxyl groups and the relationships of any parts of their chemical structure [31] . 


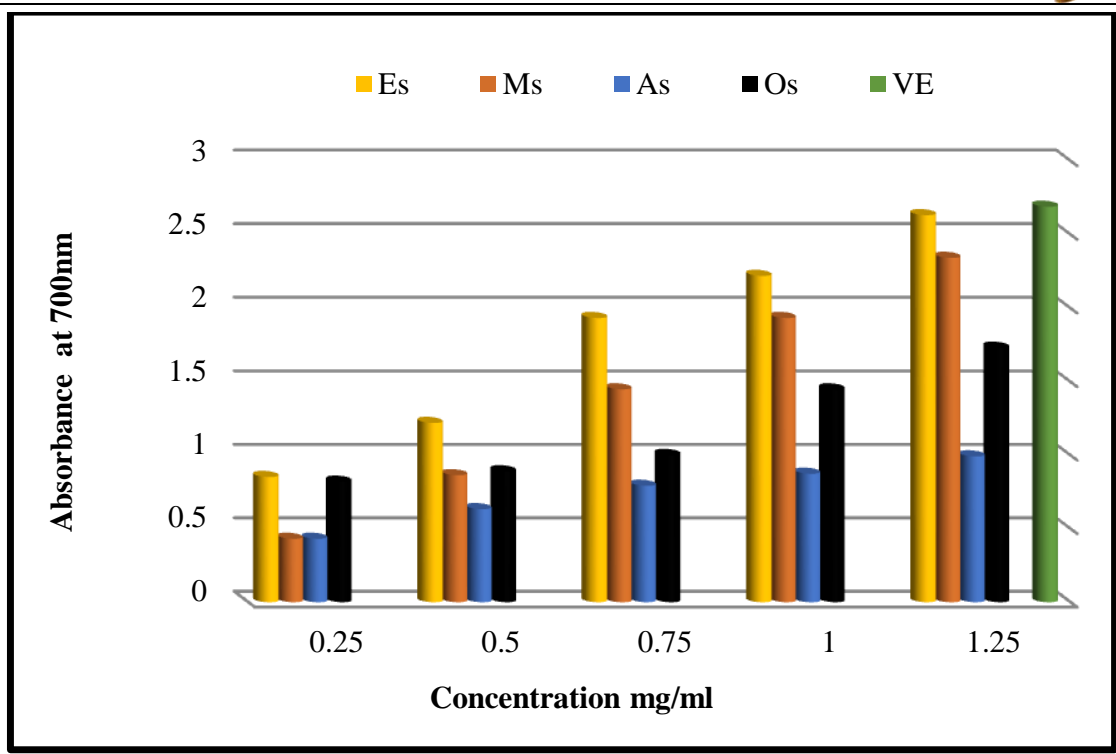

FIGURE 10. Reducing power of Zs extracts.

\section{- Chelating Ability of Ferrous Ion}

Chelating of iron ions activity of Zs obtained from ethanolic extract $60.93 \%$, methanolic extract $52.32 \%$, oil extract $52.75 \%$ and aqueous extract $44.11 \%$ was compared with Ethylene Di-amine Tetra acetic acid Di-sodium (EDTA) $92.00 \%$ at $1.25 \mathrm{mg} / \mathrm{ml}$ is shown in Figure 11 . Zs extract obtained using ethanol or methanol higher metal chelating activity than that extracted with water $(P<0.05)$. Our results are an agreement with those reported by [32] who founded that the Date seed extract obtained from $20 \%(\mathrm{v} / \mathrm{v})$ ethanol and $40 \%(\mathrm{v} / \mathrm{v})$ acetone extraction showed the highest metal chelating activity . This could be due to the fact that phenolic compounds being extracted from the date seed could play the major role in metal chelating [33].

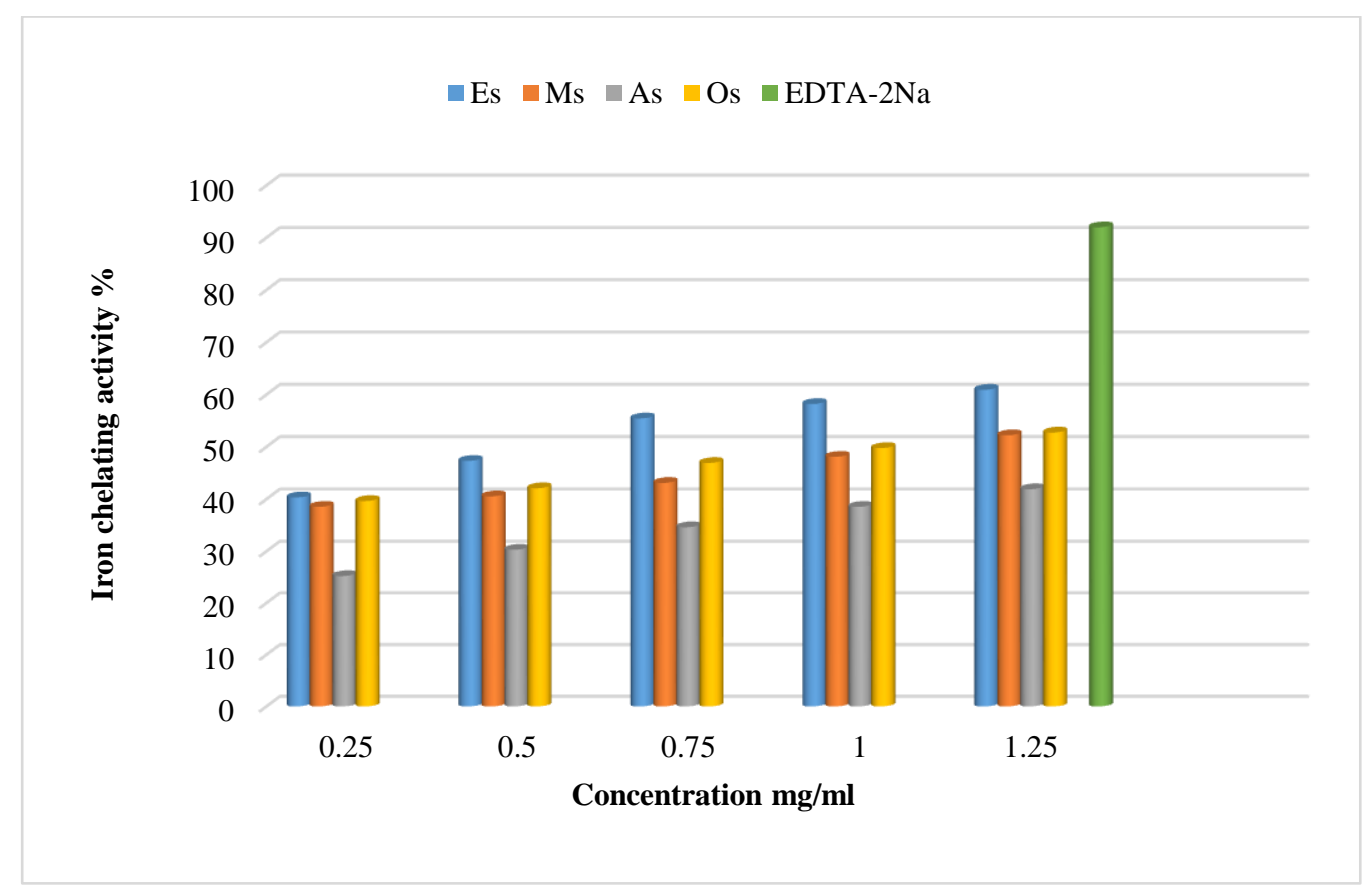

FIGURE 11. Chelating Ability of Zs Extracts.

- Effect of Zs on Lipid Oxidation of Beef Patties

- Chemical Indicators 


\section{A-Peroxide Value (PV)}

There was a significant decrease $(\mathrm{P}<0.05)$ in peroxide value in beef patties treated with ethanolic extracts of date seed compared with control that reach peroxide value to 5.87 meqlkg after 10-days of refrigerated storage . Impact of Es extract on lipid oxidation in beef patties is shown in Figure 12 . Also Es at higher concentration $(0.1 \%)$ was more effective in lowering the formation of PV , compared with that with lower concentration $(0.05 \%)$. The results indicated that Es extract, especially Es at the concentration of $0.1 \%$, effectively retarded lipid oxidation in beef patties . The ability of Es to retard lipid oxidation in beef patties might be caused by their phenolic and flavonoid contents and related with their ability to donate electron or hydrogen atom .

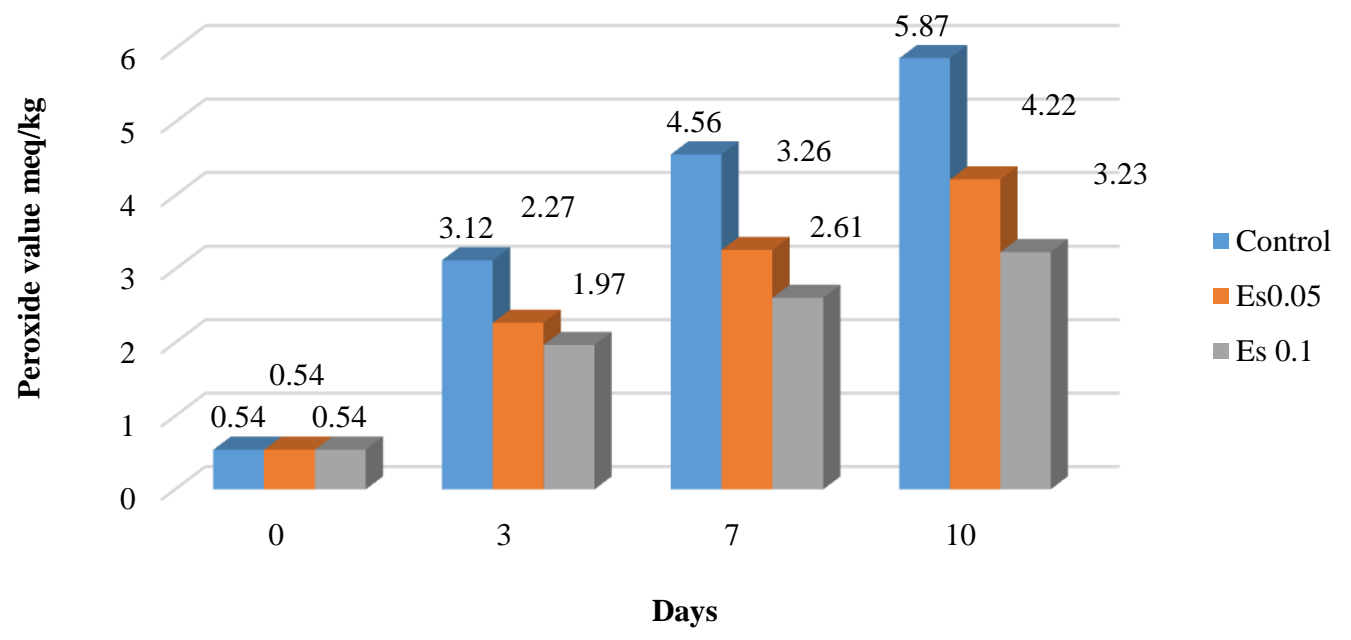

\section{$B$ - Thiobarbituric Acid (TBA)}

Impact of Es extract on TBA formation in beef patties during 10 days of refrigerated storage is shown in figure 13 . TBA values of control increased continuously during 10 days of refrigerated storage $(P<0.05)$, which indicates that the control underwent lipid oxidation at a higher degree. When the beef was incorporated with Es, the TBA formation was inhibited greatly, compared to control $(P<0.05)$ that reach to 3.93 malonaldehyde/kg after 10 -days of refrigerated storage , indicating that Es could effectively retard lipid oxidation in beef patties. Extracts produced from different leaves and fruit seed were reported to have inhibitory effect on the formation of TBA in fish and meat model system [34-35 ]. Higher concentration $(0.1 \%)$ of Es extract was more effective than lower concentration $(0.05 \%)$ in retarding the formation of lipid oxidation products . The preventive effect of Es on lipid oxidation could be attributed to the presence of different phenolic compounds. Therefore, Es extract containing different phenolic compounds could be a promising antioxidant and play an important role in preventing lipid oxidation in beef patties .

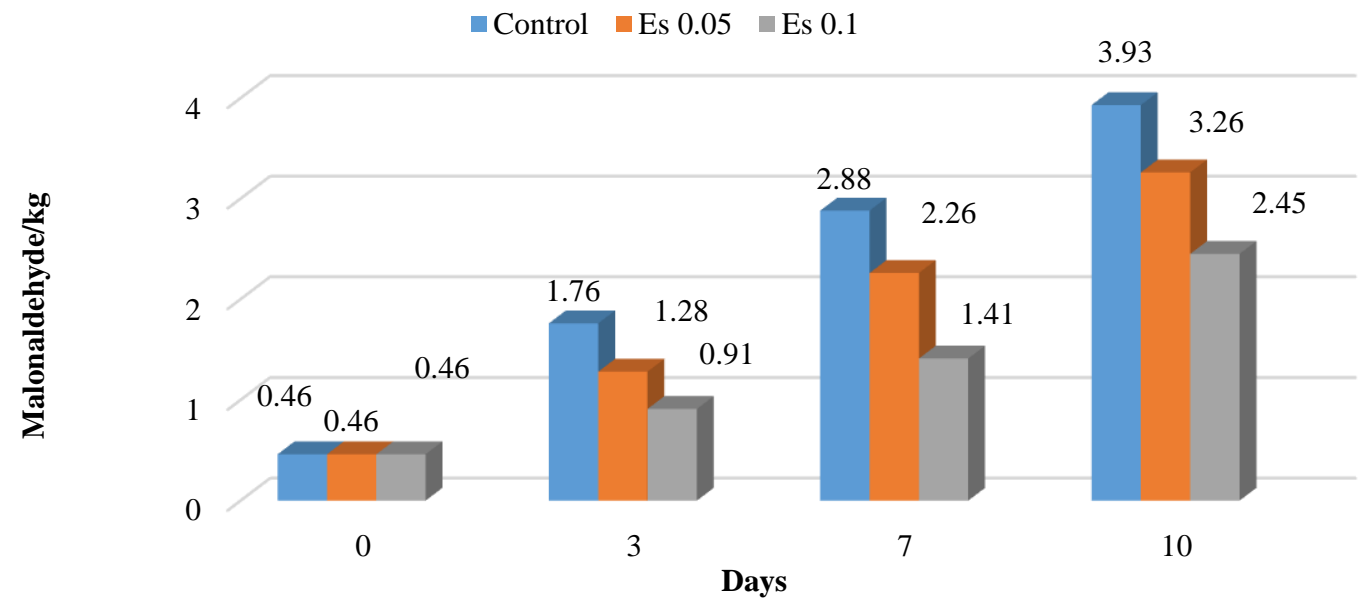

FIGURE 13. Impact of Es extract on TBA value during 10 days of refrigerator storage. 


\section{CONCLUSION}

The high amounts of phenolics, flavonoids, antioxidants and the good proximate composition require a high valorisation of this by-product using it as ingredient to enhance the nutritional value of some functional foods for human and animals consumption .

\section{ACKNOWLEDGEMENTS}

The authors would like to give thanks to Department of Food Science, College of Agriculture, University of Basrah for using lab.

\section{REFERENCES}

[1] Dammak,I.;Boudaya, S.; Abdallah, F. B.;Besbes, S.; Attia , H.; Turki,H. and Hentati, B. (2010). Date seed oil inhibits hydrogen peroxide-induced oxidative stress in human epidermal keratinocytes. International Journal of Dermatology. 49:262268.

[2] Kristbergsson, K. and Ötles ,S.(2016). Functional properties of traditional foods . 1st ed .(p.258) . US : Springer .

[3] Saafi-Ben Salah, EB.; Flamini, G.; El-Arem, A.;Issaoui,M.; Dabbou, S.; Ben Yahia, L.;Ferchichi , A.; Hammami , M.and Achour, L.(2012). Compositional characteristics and aromatic profile of date palm seeds from seven varieties grown in Tunisia . Int. J Food Sci. Technol., 47:1903- 1908.

[4] Aljazy, N. A. S., \& Abdulstar, A. R. (2021). Potential Effects Of Natural Antioxidants In The Treatment Of Some Viral Diseases : Review. Al-Qadisiyah Journal For Agriculture Sciences (QJAS), 11(2), 1-11.

[5] Saryono,S.; Eliyan ,J. ;Herdiati , D. ; Khikmatullah ,A.A.; Silvana, C.P. and Adi, HP.(2017). Anti- atherogenic properties of Deglet Noor Date Seeds (phoenix dactylifera) methanol extract on Diet-induced Hyper cholesterolemic Rats . Iop conf . Series : Meterials Science and Engineering 172, 012046 doi : $10.1088 \mid 1757-899$ X | $172|1| 0120$ - 46.

[6] Fathi, H.A. (2005). Date Palm. Life Trees. Arabian Publ. distribution house. 1st ed. Cairo.

[7] A.O.A.C. (1980) . Official methods of analysis of association of official analytical chemistis , Washington , U.S.A.

[8] Ratheesh, M. and Helen, A. (2007). Anti inflammatory of Ruta graveolens .L. on carrageenan induced paw edema in wistar male rats. Africian . J. Biotechnology . 6(10): 1209-1211

[9] Elmastas, M.;Cinkilic, S. and Aboul-Enein , H.Y.(2015). Antioxidant Capacity and Determination of Total Phenolic Compounds in Daisy (Matricaria Chamomilla,Fam.Asteraceae . World Journal of Analytical Chemistry .3:9-14.

[10] Bligh, E.G.and Dyer, W.J.(1959) . Arapid method for total lipid extraction and purification .Can .J. Biochem. Physiol .37:911-917.

[11] Al-helfy, S.A.M.(2009). Extraction ,Separation and Identification of phenolic compounds and their derivative from plant sources and their using as antioxidant and antimicrobial and application in food system . Phd. Thesis . Agricultural college. Basrah university .

[12] Shimada, K.; Fujikawa,K. ; Yahara,K. and Nakamura,T.(1992). Antioxidative properties of xanthin on autoxidation of soybean oil in cyclodextrin emulsion .J.Agric .Food Chem .40:945-948.

[13] Oyaizu, M. (1986). Studies on products of browning reaction: antioxidative activites of products of browning reaction prepared from glucosamine .Japanese Journal of Nutrition .44:307-315.

[14] Decker, E.A. and Welch, B.(1990) . Role of Frritin as a lipid oxidation Catalyst in muscle Food .J.Agri. Food Chem .

[15] Egan,H.;Kirk,R.S.and Sawyer,R(1981).Chemical analysis of food. Logman Scientific and Technical New York .

[16] Pearson, D.(1970). The chemical Analysis of Food .Chemical Publishing Company , INC. New York.

[17] Al-Rawi, K.M .\& Abdul-Aziz, M.K. (2000). Design and Analysis of Experiments Agricultural. Foundation National Library for Printing and Publishing .Univ.Mosul. .30-32

[18] Noid, M.H. (2013). Study comparison to three local verities of oil date seed and their entering in some food systems . Msc. Thesis. Agricultural college. Basrah university .

[19] Al-Juhaimi,F.;Ghafoor,K. and Özcan,M.M.(2012). Physical and chemical properties , antioxidant activity ,total phenol and mineral profile of seeds of seven different date fruit (Phoenix dactylifera L.)varieties.IntJFood Sci. Nutr;63:84-9.

[20] Al-Farsi, M. ; Alasalvar,C. ;Al-Abid, M.; Alshoaily,K.;Amry, M. and Al-Rawahy,F.(2007). Compositional and functional characteristics of dates , syrups, and their products. Food Chem; 104:943-7.

[21] Mistrello , J. ; Sirisena, SD.; Ghavamic, A.;Marshalld,R.J.and Krishnam ,S. (2014). Determination of the antioxidant capacity ,total phenolic and flavonoid contents of seeds from three commercial varieties of culinary dates . Int.J.Food Stud. 3:34-44.

[22] Al-buddiu , H ; Neama , B .and Khudaira ,H.A.(2016). Determination of essential oil components extraction from Capparis spinosa using by GC-MS. Tishreen University Jounal for Research and Scientific Studies . Essential scientific series. 38(4).

[23] Sonntag, N.O.V. (1982) . 'Glycerolysis of fats and methyl esters - status, review and critique '. Journal of the American oil Chemists Society . 59 (10): $795-802$.

[24] Abiola, T.; Dibie, D.C.; Akinwale, O.J and Shoumuyiwa,OA.(2018). Assessment of the Antidiabetic Potential of the ethanolic extract of date palm (Phoenix dactylifera ) seed in Alloxan-Induced diabetic rats. J Diabetes Metab . 9:1.

[25] Ariantari ,N.P.;Chandra ,YS. and Swastini , DA.(2010). Cholesterol-lowering activity test of herbal honey products on the market in the diet - induced high fat rat. J. Chem. 4.

[26] Al-Farsi , M.A.; Lee , C.Y. (2008). Optimization of phenolics and dietary fibre extraction from date seeds .Food chemistry .108(3): 977-985.

[27] Al-Farsi, M. ; Alasalvar,C. ;Al-Abid, M.; Alshoaily,K.;Amry, M. and Al-Rawahy,F.(2007). Compositional and functional characteristics of dates , syrups, and their products. Food Chem; 104:943-7. 
[28] Thouri , A.; Chahdoura , H.; El -Arem,A. ; Flamini , G.; Jelled , A. and Achour , L. (2017). Antioxidant activity , volatile and non volatile composition of two phoenix dactylifera L. By products . Journal of coastal life medicine . 5(6) :254-260.

[29] Siddhuraju, P . and Becker, K. (2006). The antioxidant andfree radical scavenging activities of processed cowpea (Vigna unguiculata (L.) Walp .) seed extracts . Food Chemistry 101(1) : 10-19 .

[30] Leong, L.P. and Shui ,G.(2002) . An investigation of antioxidant capacity of fruits in Singapore markets . Food Chemistry . 76(1): 69-75 .

[31] Eleazu ,C.O. ; Amajor ,J.U.; Ikpeama , A.I. and Awa, E. (2011). Studies their nutritional composition , antioxidant activites , Functional properties and microbial loads of the flours of 10 elite cassava varieties .Asian .J.Clin .Nutr., 3(1): 33-39.

[32] Maqsood , S.;Kittiphattanabawon ,P.; Benjakul ,S.; Sumpavapol, P. and Abushelaibi, A. (2015). Antioxidant activity of date (phoenix dactylifera var.Khalas ) seed and its preventive effect on lipid oxidation in model system . Int. Food Res. J. 22 : $1180-1188$

[33] Sarikurkcu, C. ; Tepe, B.; Yamac, M. (2008) . Evaluation of the antioxidant activity of four edible mushrooms from the Central Anatolia , Eskisehir- Turkey : Lactarius deterrimus, Suillus collitinus, Boletus edulis and Xerocomus chrysenteron. Bioresource Technology 99: 6651-6655 .

[34] Arun,K.D. and Rajkumar ,V.(2011).Antioxidant effect of curry leaf powder on quality of ground and cooked goat meat .International Food Research Journal .18(2): 563-569.

[35] Brannan,R.G.and Mah,E.(2007). Grape seed extract inhibits lipid oxidation in muscle from different species during refrigerated and frozen storage and oxidation catalyzed by peroxynitrite and iron/ascorbate in a pyrogallol red model system .Meat Science. 77(4):540-546. 